\section{Fatores associados a alterações vocais em professoras}

\author{
Factors associated with voice disorders among \\ women teachers
}

\footnotetext{
${ }^{1}$ Departamento de Saúde, Universidade Estadual de Feira de Santana, Feira de Santana, Brasil.

2 Faculdade de Medicina, Universidade Federal da Bahia, Salvador, Brasil.

Correspondência E. J. F. B. Reis Departamento de Medicina Preventiva e Social, Faculdade de Medicina, Universidade Federal da Bahia.

Rua Sabino Silva 320 apto. 802, Salvador, $B A$ 40155-250, Brasil. eduardofreis@uol.com.br
}

\begin{abstract}
This study aimed to identify risk factors for voice disorders (hoarseness in the previous six months as an initial manifestation, and vocal cord nodules as a more severe manifestation of overt disease) among teachers. The cross-sectional study included 747 women teachers from elementary and middle schools in the public school system in Vitória da Conquista, Bahia State, Brazil. Data were collected using a self-applied, standardized questionnaire. Hoarseness in the previous six months was reported by $59.2 \%$ of teachers and vocal cord nodules by 12.9\%. Logistic regression techniques showed that hoarseness was statistically associated with $\geq 24$ classroom hours per week, work in more than one school, and having to make an effort to speak. Vocal cord nodules were associated with working $\geq 5$ years as a teacher, work in more than one school, working at another job besides teaching, and having to make an effort to speak. In conclusion, voice disorders are frequent among schoolteachers and are associated with multiple occupational risk factors, besides purely biological ones.
\end{abstract}

Vocal Cords; Voice Disorders; Working Conditions

\author{
Tânia Maria de Araújo ${ }^{1}$ \\ Eduardo José Farias Borges dos Reis 2 \\ Fernando Martins Carvalho 2 \\ Lauro Antonio Porto 2 \\ Israel Costa Reis 2 \\ Jonathan Moura de Andrade 2
}

\section{Introdução}

A relação entre a ocorrência de disfonias e o uso profissional da voz tem sido destacada atualmente na literatura. Entre os fatores de risco para os problemas de voz, destacam-se as condições inadequadas do ambiente de trabalho, elevada jornada de trabalho, falta de conhecimento quanto ao uso correto da voz e a baixa procura por atendimento especializado ${ }^{1}$. A voz representa uma das ferramentas básicas no desenvolvimento do trabalho de algumas profissões, aparecendo como fator preponderante na expressão de significados e enriquecimento do discurso. Esse é o caso de professores, advogados, cantores, telefonistas, locutores, dentre outros, que são classificados como "usuários" profissionais da voz 2 .

No grande espectro que abrange os usuários profissionais da voz está o professor, que depende, em boa parte, da voz e da fala para o desempenho adequado de sua profissão. Portanto, as questões da voz do professor devem ser encaradas como de voz profissional e vêm-se constituindo como objeto de pesquisa específico no campo da saúde ocupacional. A Organização Internacional do Trabalho (OIT) ${ }^{3}$ considera o professorado como a categoria de maior risco de contrair enfermidades profissionais da voz, pois o tipo de voz mais propenso a causar danos aos órgãos vocais é a "voz projetada", aquela utilizada para exercer influência sobre outras pessoas, 
para chamar atenção, tentar persuadir e ganhar a audiência.

No contexto pedagógico, espera-se que a voz seja clara, com boa sonoridade, com ritmo e velocidade adequados, boa projeção e coordenação com a respiração, refletindo o equilíbrio das estruturas do trato vocal. Entretanto, nem sempre as condições para o uso adequado da voz estão disponíveis. Condições do ambiente de trabalho (acústica, nível de competição sonora ambiental, umidade, poeira), características do trabalho (extensão da jornada de trabalho, tempo de exposição na atividade docente, manutenção de múltiplos empregos) e falta de preparo/treinamento para o uso adequado da voz são fatores que podem contribuir para o abuso vocal, gerando alterações vocais em diferentes níveis de freqüência e severidade 4,5 .

Quando as condições para o uso adequado da voz não estão disponíveis, impõem-se mudanças no padrão de uso da voz, através de ajustes fonatórios compensatórios, adaptações patológicas, hábitos e comportamentos vocais prejudiciais ao aparelho fonador. Tais mudanças, muitas vezes, constituem abuso adicional e resultam em maior dano tecidual 6 .

Alguns professores, diante da demanda diária do uso da voz associada às condições inadequadas de trabalho, adquirem intuitivamente comportamentos vocais que possibilitam a utilização da voz com certa sobrecarga do aparelho laríngeo, mas que os mantém, por um longo período, sem sintomas. No entanto, uma parcela destes profissionais não dispõe de tais recursos compensatórios, fazendo assim uso inadequado e nocivo da voz, e desenvolvem alterações vocais em diferentes tipos e graus de severidade 7 .

O esforço vocal é a principal causa dos transtornos da voz em docentes 8 . Dentre as alterações vocais mais relevantes para a prática docente, destacam-se a rouquidão, em função de sua elevada freqüência, e os calos nas cordas vocais, pelo nível de comprometimento no uso da voz 8,9.

A avaliação dos fatores associados às alterações vocais, nas diferentes dimensões do problema (aspectos sócio-demográficos, características do trabalho e hábitos de uso vocal) poderá contribuir para que os programas de intervenção possam ser elaborados a partir da compreensão dos fatores, em contextos concretos, que podem determinar ou contribuir para a ocorrência do evento estudado.

O problema aqui investigado, as alterações vocais, além do impacto sobre a saúde do professor, afeta negativamente seu desempenho nas atividades de ensino, constituindo-se numa fonte permanente de frustração, insatisfação e estresse, e, não raro, de afastamento temporário ou permanente da sala de aula, o que contribui para a diminuição da qualidade de vida dos docentes e do processo de ensino-aprendizagem 10 .

O presente estudo objetivou identificar fatores associados às alterações vocais em professoras da rede municipal de ensino de Vitória da Conquista, Bahia, Brasil, considerando duas alterações vocais de significativa importância no adoecimento vocal entre docentes: a rouquidão e os calos nas cordas vocais.

\section{Material e métodos}

Foi realizado um estudo epidemiológico de corte transversal, de abrangência censitária, entre professores da rede municipal de ensino da cidade de Vitória da Conquista. A rede municipal de ensino abrange o ensino da pré-escola e fundamental (anos escolares de 1a à 8a série), incluindo escolas na zona urbana e rural do município.

Foram considerados elegíveis para o estudo todos os professores em efetivo exercício profissional, independentemente do tipo de vínculo empregatício existente. Foram excluídos do estudo professores de educação física, xadrez, informática e de língua estrangeira em função das características de trabalho diferenciadas das atividades desenvolvidas por esses profissionais. O número de professores considerados elegíveis para o estudo totalizou 967.

Foram estudados 808 professores, representando um percentual de resposta de $83,5 \%$. Oitenta $(8,3 \%)$ professores recusaram-se a participar e $79(8,2 \%)$ não foram localizados. Dos docentes estudados, 747 eram mulheres e 47 eram homens. Perdeu-se informação sobre a variável sexo para 14 pessoas. Em função de possíveis variações dos eventos estudados (rouquidão e calos nas cordas vocais) segundo o sexo e do pequeno número de homens estudados, optou-se, neste estudo, por restringir a análise apenas às mulheres $(\mathrm{N}=747)$.

Para a coleta de dados foi utilizado um formulário auto-aplicado contendo cinco blocos de questões: (I) informações gerais de identificação do professor (sexo, escolaridade, idade, situação conjugal, filhos); (II) informações sobre a atividade de trabalho do professor na escola escolhida (tempo de trabalho na profissão, carga horária total de trabalho na semana, turno de trabalho, número de alunos); (III) informações sobre aspectos psicossociais do trabalho, utilizando o Job Content Questionnaire (JCQ) 11, destinado a avaliar controle do professor sobre suas atividades, demanda psicológica envolvida nessas atividades e suporte social; 
(IV) informações sobre a saúde do professor, para avaliar a situação global da saúde vocal dos docentes (queixas e sintomas como rouquidão, cansaço ao falar, disfonias em geral e calos nas cordas vocais). A avaliação da saúde vocal dos professores foi feita considerando: (1) características do uso da voz, (2) ocorrência de alterações vocais e (3) tipos de tratamentos buscados; (V) informações sobre atividades domésticas realizadas.

A coleta de dados foi realizada no período de setembro a novembro de 2001, por estudantes de medicina devidamente treinados. Um manual de instrução foi elaborado para orientar os procedimentos durante as entrevistas. Contatos prévios com a direção das escolas foram feitos a fim de obter permissão para a realização da pesquisa. As entrevistas foram realizadas nas escolas onde as professoras trabalhavam, mantendo-se o anonimato das mesmas. Os questionários foram entregues em envelopes fechados. As professoras receberam previamente o termo de consentimento para realização da pesquisa e apenas participaram aquelas que assinaram o referido documento. A pesquisa foi submetida ao Comitê de Ética em Pesquisa do Hospital Universitário Edgard Santos da Universidade Federal da Bahia, que aprovou a sua execução.

Do amplo espectro de alterações vocais, selecionaram-se duas manifestações clínicas de alteração vocal de gravidade diferenciada, referidas pelas professoras: uma sintomatologia inicial, representada por rouquidão nos últimos seis meses; e uma doença mais severa, já instalada, representada por calos nas cordas vocais.

Inicialmente foram calculadas as freqüências dos aspectos vocais investigados (características do uso da voz e tipos de sintomatologia referidos). Para avaliação dos fatores associados às alterações vocais de interesse (rouquidão nos últimos seis meses e diagnóstico de calos nas cordas vocais), foram incluídas na análise variáveis referentes a: (1) características sócio-demográficas (renda, idade, escolaridade, sobrecarga doméstica); (2) hábitos de vida (tabagismo e etilismo); (3) características do trabalho docente (tempo de trabalho como professor, horas semanais de trabalho docente, número de turmas e alunos, tipo de vínculo empregatício, modalidade de ensino, trabalho em mais de uma escola, exercício de outra atividade, localização da escola na zona urbana ou rural); (4) aspectos psicossociais do trabalho (controle, demanda e suporte social) e (5) características do uso da voz: gritar ou falar alto, fazer força para falar.

Para a avaliação da associação entre fatores associados às alterações vocais, na análise bivariada calcularam-se razões de prevalência (RP) e seus respectivos intervalos de confiança, tomando-se como critério de associação estatística significante o nível de 95\% de confiança. Subseqüentemente, uma análise de regressão logística múltipla incluiu todas as co-variáveis de interesse. A regressão logística múltipla, técnica indicada como apropriada para análise da relação entre variáveis discretas ou contínuas e uma variável dependente binária 12 , como as aqui estudadas, foi aplicada para identificar fatores associados significantemente à variável de desfecho, ajustando-se concomitantemente o efeito de uma variável pelo das demais variáveis de interesse incluídas na análise. Para a pré-seleção das co-variáveis, observaram-se aquelas que apresentavam valor $\mathrm{p}$, obtido pelo teste de razão de verossimilhança, menor ou igual a 0,25 , em análises de regressão logística univariadas nas quais apenas a constante e uma variável de cada vez estavam contidas no modelo. Em seguida, definindo-se o nível de significância de 0,20 como critério de inclusão de variáveis 12 , foi usado um modelo de regressão logística com a variável independente de interesse, as co-variáveis pré-selecionadas e seus respectivos termos de interação de primeira ordem. O modelo final foi obtido utilizando-se o método de "trás para frente", com reavaliação a cada etapa. Apenas as variáveis e os termos de interação correspondentes que alcançaram, nesta etapa de análise, o nível definido de significância estatística no teste da razão de verossimilhança (20\%) foram mantidos no modelo final.

Todas as variáveis investigadas como fatores associados às alterações vocais estudadas, descritas acima, foram também incluídas na análise de regressão logística múltipla no intuito de avaliar o melhor modelo para cada um dos desfechos investigados (rouquidão nos últimos seis meses e calos nas cordas vocais).

As variáveis independentes presentes no modelo de análise selecionado foram avaliadas quanto à colinearidade, por meio dos valores de tolerância para as estimativas, de fatores de inflação da variância com as estimativas do parâmetro e dos índices de condição. A análise feita não revelou presença de colinearidade. Portanto, segundo os critérios comumente recomendados 12 não se observou colinearidade entre as variáveis estudadas.

Considerando que a prevalência da variável rouquidão na população investigada foi elevada, distanciando-se dos parâmetros estimados para odds ratio (OR), procedeu-se ao cálculo das estimativas de RP e de seus respectivos intervalos de $95 \%$ de confiança (IC95\%), utilizando-se dos procedimentos do método delta 13 . 


\section{Resultados}

Das 747 professoras estudadas, observou-se predomínio das faixas etárias mais jovens (até 39 anos: 70,1\%) (Tabela 1). A média de idade foi de 34,4 anos (desvio-padrão - DP = 8,5). Mais da metade das professoras $(56,2 \%)$ possuía companheiros. A maioria das docentes $(69,6 \%)$ tinha formação de nível médio. O consumo de bebi-

Tabela 1

Características sócio-demográficas e do trabalho das professoras da rede municipal de ensino de Vitória da Conquista, Bahia, Brasil, 2001.

\begin{tabular}{|c|c|c|}
\hline \multirow[t]{2}{*}{ Variável/Categoria } & \multicolumn{2}{|c|}{ População estudada } \\
\hline & $\mathrm{n}$ & $\%$ \\
\hline \multicolumn{3}{|l|}{ Faixa etária ( $\mathrm{N}=747)$} \\
\hline Até 29 anos & 228 & 30,5 \\
\hline 30-39 anos & 296 & 39,6 \\
\hline 40-49 anos & 146 & 19,6 \\
\hline 50 anos ou mais & 77 & 10,3 \\
\hline \multicolumn{3}{|l|}{ Situação conjugal (N = 740) } \\
\hline Solteiro & 262 & 35,4 \\
\hline Casado & 389 & 52,6 \\
\hline Viúvo & 20 & 2,7 \\
\hline Separado & 69 & 9,3 \\
\hline \multicolumn{3}{|l|}{ Escolaridade ( $\mathrm{N}=739)$} \\
\hline Superior & 225 & 30,4 \\
\hline Ensino médio/técnico & 514 & 69,6 \\
\hline \multicolumn{3}{|l|}{ Zona de trabalho $(\mathrm{N}=747)$} \\
\hline Rural & 324 & 43,4 \\
\hline Urbana & 423 & 56,6 \\
\hline \multicolumn{3}{|c|}{ Modalidade de ensino em que leciona $(\mathrm{N}=632)$} \\
\hline Pré-escola & 53 & 8,4 \\
\hline Fundamental I & 418 & 66,1 \\
\hline Fundamental II & 117 & 18,5 \\
\hline Pré-escola + fundamental I & 37 & 5,9 \\
\hline Fundamental I + II & 7 & 1,1 \\
\hline \multicolumn{3}{|l|}{ Tipo de vínculo $(\mathrm{N}=724)$} \\
\hline Efetivo & 629 & 86,9 \\
\hline Temporário & 95 & 13,1 \\
\hline \multicolumn{3}{|c|}{ Trabalho em duas ou mais escolas $(\mathrm{N}=676)$} \\
\hline Sim & 211 & 31,2 \\
\hline Não & 465 & 68,8 \\
\hline \multicolumn{3}{|c|}{ Outra atividade remunerada $(N=646)$} \\
\hline Sim & 38 & 5,9 \\
\hline Não & 608 & 94,1 \\
\hline \multicolumn{3}{|l|}{ Bebe $(N=727)$} \\
\hline Sim & 140 & 19,3 \\
\hline Não & 587 & 80,7 \\
\hline \multicolumn{3}{|l|}{ Fuma $(\mathrm{N}=702)$} \\
\hline Sim & 50 & 7,1 \\
\hline Não & 652 & 92,9 \\
\hline
\end{tabular}

da alcoólica foi referido por $19,3 \%$ das docentes; $7,1 \%$ eram fumantes.

A modalidade de ensino mais freqüente foi a de ensino apenas no fundamental I (de 1ạ a 5ạ série), envolvendo $66,1 \%$ das pesquisadas. Embora $56,3 \%$ das professoras lecionassem em escolas da zona urbana, registrou-se elevado percentual de professoras ensinando em escolas da zona rural $(43,4 \%)$. Vínculo de trabalho estável foi predominante $(86,9 \%)$. Aproximadamente um terço dos professores referiu trabalhar em mais de uma escola, e 5,9\% relataram ter outra atividade remunerada, além da atividade de ensino.

O tempo médio de trabalho como educador foi de 10,6 (DP = 6,6 anos). A média de turmas por professora foi 2,3, com 29,3 alunos, em média, por sala de aula. A carga horária total de trabalho, como educador, em sala de aula (considerandose todas as escolas nas quais o professor trabalhava), foi de 32,9 horas semanais ( $D P=10,6$ ). A renda mensal média foi de $\mathrm{R} \$ 433,80(\mathrm{DP}=\mathrm{R} \$$ $169,90)$.

O uso intensivo da voz foi referido por $91,7 \%$ das professoras. As duas alterações vocais mais referidas foram cansar quando fala $(69,1 \%)$ e sentir a voz rouca ou fraca após o dia de trabalho (67,9\%) (Tabela 2). A prevalência de rouquidão nos últimos seis meses foi elevada, atingindo $59,2 \%$ das docentes. Calos nas cordas vocais, desde que começaram a trabalhar como docentes, foram relatados por $12,9 \%$; $25,6 \%$ referiram perda temporária da voz. Tratamento com otorrinolaringologista foi relatado por $42,9 \%$ das professoras, enquanto apenas $4,9 \%$ realizaram tratamento fonoaudiológico (Tabela 2). Os sintomas específicos relacionados à garganta mais freqüentemente referidos foram: sensação de ressecamento $(66,5 \%)$, coceira $(51,5 \%)$, pigarro $(49,7 \%)$, dor $(43,6 \%)$, ardor $(39,4 \%)$ e sensação de aperto ou bolo (30,7\%).

Análises bivariadas revelaram que a queixa de rouquidão nos últimos seis meses estava estatisticamente associada aos seguintes fatores: trabalhar como docente $\geq 5$ anos ( $R P=1,26)$, ter $\geq 24$ horas de trabalho por semana em sala de aula em todas as escolas $(\mathrm{RP}=1,33)$, trabalhar em duas ou mais escolas $(\mathrm{RP}=1,15)$, usar a voz de forma intensa $(\mathrm{RP}=1,66)$, usar a voz gritando/falando alto $(\mathrm{RP}=1,27)$ e fazer força para falar $(\mathrm{RP}=1,54)$ (Tabela 3). Diagnóstico referido de calos nas cordas vocais estava estatisticamente associado aos seguintes fatores: idade $\geq 27$ anos $(R P=2,21)$, beber $(R P=1,65)$, trabalhar como docente $\geq 5$ anos ( $\mathrm{RP}=2,44)$, manter vínculo de trabalho estável $(\mathrm{RP}=2,22)$, ter $\geq 25$ alunos $(\mathrm{RP}=2,06)$, trabalhar em duas ou mais escolas ( $\mathrm{RP}=1,87)$, trabalhar em outra atividade além da docência $(\mathrm{RP}=2,29)$ e fazer força para falar $(\mathrm{RP}=1,66)$ (Tabela 4$)$. 
Freqüência (\%) de respostas afirmativas a questões sobre a voz das professoras da rede municipal de ensino de Vitória da Conquista, Bahia, Brasil, 2001

\begin{tabular}{|c|c|c|c|}
\hline \multirow[t]{2}{*}{ Questões sobre a voz } & \multirow[t]{2}{*}{$\mathbf{N}$} & \multicolumn{2}{|c|}{ Sim } \\
\hline & & $\mathbf{n}$ & $\%$ \\
\hline \multicolumn{4}{|l|}{ Características do uso } \\
\hline Usa a voz de forma intensiva & 726 & 666 & 91,7 \\
\hline Faz força para ser ouvido & 724 & 418 & 57,7 \\
\hline Grita demais & 735 & 309 & 42,0 \\
\hline \multicolumn{4}{|l|}{ Referentes às alterações vocais } \\
\hline Cansa-se quando fala & 740 & 511 & 69,1 \\
\hline Sua voz fica rouca ou fraca após um dia de trabalho & 729 & 495 & 67,9 \\
\hline Sua voz some ou muda repentinamente de tom & 732 & 444 & 60,7 \\
\hline Perda temporária da voz & 711 & 182 & 25,6 \\
\hline Rouquidão nos últimos 6 meses & 730 & 432 & 59,2 \\
\hline Calos nas cordas vocais & 740 & 89 & 12,9 \\
\hline \multicolumn{4}{|l|}{ Referentes à busca de tratamento } \\
\hline Fez tratamento com otorrinolaringologista & 793 & 332 & 41,9 \\
\hline Fez tratamento com fonoaudiólogo & 798 & 39 & 4,9 \\
\hline
\end{tabular}

Tabela 3

Razões de prevalência (RP) e intervalos de 95\% de confiança (IC95\%) de fatores associados a queixas de rouquidão nos últimos seis meses em professores da rede municipal de ensino de Vitória da Conquista, Bahia, Brasil, 2001.

\begin{tabular}{|c|c|c|c|}
\hline \multirow[t]{2}{*}{ Variáveis avaliadas } & \multicolumn{3}{|c|}{ Rouquidão nos últimos seis meses } \\
\hline & $\mathbf{N}$ & RP & IC95\% \\
\hline \multicolumn{4}{|l|}{ Características sócio-demográficas (referente) } \\
\hline Idade $\geq 27$ anos ( $<27$ anos) & 730 & 1,13 & $0,95-1,33$ \\
\hline Escolaridade superior (< superior) & 721 & 1,07 & $0,94-1,22$ \\
\hline Renda mensal $\geq \mathrm{R} \$ 360,00(<\mathrm{R} \$ 360,00)$ & 729 & 1,12 & $0,96-1,31$ \\
\hline Sobrecarga doméstica alta e média (baixa) & 671 & 1,12 & $0,97-1,29$ \\
\hline \multicolumn{4}{|l|}{ Hábitos de vida } \\
\hline Fuma (não fuma) & 686 & 1,05 & $0,83-1,31$ \\
\hline Bebe (não bebe) & 712 & 1,01 & $0,87-1,18$ \\
\hline \multicolumn{4}{|l|}{ Características do trabalho docente } \\
\hline Trabalho como docente $\geq 5$ anos ( $<5$ anos) & 730 & 1,26 & $1,06-1,50$ \\
\hline Vínculo de trabalho estável (temporário) & 708 & 1,24 & $1,00-1,54$ \\
\hline Ensina no fundamental II (pré-escola/fundamental I) & 617 & 1,03 & $0,87-1,21$ \\
\hline Leciona $\geq 4$ turmas ( $<4$ turmas) & 730 & 1,00 & $0,85-1,16$ \\
\hline Número médio de alunos $\geq 25$ ( $<25$ alunos) & 730 & 1,05 & $0,89-1,24$ \\
\hline Trabalha $\geq 24$ horas/semana em sala de aula ( $<24$ horas/semana) & 680 & 1,33 & $1,12-1,58$ \\
\hline Trabalha em duas ou mais escolas (uma escola) & 661 & 1,15 & $1,01-1,30$ \\
\hline Trabalha em outra atividade além docência (não) & 637 & 0,97 & $0,73-1,28$ \\
\hline \multicolumn{4}{|l|}{ Aspectos psicossociais do trabalho } \\
\hline Baixo controle (alto controle) & 628 & 1,02 & $0,90-1,16$ \\
\hline Alta demanda (baixa demanda) & 662 & 1,12 & $0,99-1,28$ \\
\hline Baixo suporte social (alto controle social) & 670 & 1,30 & $0,87-1,92$ \\
\hline \multicolumn{4}{|l|}{ Uso da voz } \\
\hline Uso intensivo da voz (não intensivo) & 712 & 1,66 & $1,18-2,35$ \\
\hline Usa voz gritando/falando alto (não grita/fala alto) & 721 & 1,27 & $1,13-1,77$ \\
\hline Faz força para ser ouvido (não faz força) & 628 & 1,02 & $0,90-1,16$ \\
\hline
\end{tabular}

N: número de professores incluídos na análise. 
Razões de prevalência (RP) e intervalos de 95\% de confiança (IC95\%) de fatores associados ao diagnóstico de calos nas pregas vocais em professores da rede municipal de ensino de Vitória da Conquista, Bahia, Brasil, 2001.

\begin{tabular}{|c|c|c|c|}
\hline \multirow[t]{2}{*}{ Variáveis } & \multicolumn{3}{|c|}{ Diagnóstico de calo nas cordas vocais } \\
\hline & $\mathbf{N}$ & RP & IC95\% \\
\hline \multicolumn{4}{|l|}{ Características sócio-demográficas } \\
\hline Idade $\geq 27$ anos ( $<27$ anos) & 691 & 2,21 & $1,10-4,46$ \\
\hline Escolaridade superior (< superior) & 680 & 1,28 & $0,85-1,91$ \\
\hline Renda mensal $\geq \mathrm{R} \$ 360,00(<\mathrm{R} \$ 360,00)$ & 690 & 1,10 & $0,67-1,78$ \\
\hline Sobrecarga doméstica alta e média (baixa) & 638 & 1,33 & $0,83-2,13$ \\
\hline \multicolumn{4}{|l|}{ Hábitos de vida } \\
\hline Fuma (não fuma) & 658 & 1,56 & $0,83-2,90$ \\
\hline Bebe (não bebe) & 677 & 1,65 & $1,08-2,52$ \\
\hline \multicolumn{4}{|l|}{ Características do trabalho docente } \\
\hline Trabalho como docente $\geq 5$ anos ( $<5$ anos) & 691 & 2,44 & $1,21-4,91$ \\
\hline Vínculo de trabalho estável (temporário) & 670 & 2,22 & $0,93-5,32$ \\
\hline Ensina no fundamental II (pré-escola/fundamental I) & 587 & 1,22 & $0,74-2,02$ \\
\hline Leciona $\geq 4$ turmas ( $<4$ turmas) & 691 & 1,29 & $0,81-2,04$ \\
\hline Número médio de alunos $\geq 25(<25)$ & 691 & 2,06 & $1,03-4,15$ \\
\hline Trabalha $\geq 24$ horas/semana em sala de aula ( $<24$ horas/semana) & 644 & 1,28 & $0,76-2,13$ \\
\hline Trabalha em duas ou mais escolas (uma escola) & 631 & 1,87 & $1,26-2,80$ \\
\hline Trabalha em outra atividade além docência (não) & 604 & 2,29 & $1,29-4,05$ \\
\hline \multicolumn{4}{|l|}{ Aspectos psicossociais do trabalho } \\
\hline Baixo controle (alto controle) & 593 & 0,91 & $0,61-1,38$ \\
\hline Alta demanda (baixa demanda) & 625 & 1,25 & $0,83-1,88$ \\
\hline Baixo suporte social (alto controle social) & 631 & 1,34 & $0,88-1,94$ \\
\hline \multicolumn{4}{|l|}{ Uso da voz } \\
\hline Uso intensivo da voz (não intensivo) & 672 & 1,44 & $0,61-3,39$ \\
\hline Usa voz gritando/falando alto (não grita/fala alto) & 682 & 1,09 & $0,74-1,60$ \\
\hline Faz força para falar (não faz força) & 671 & 1,66 & $1,09-2,55$ \\
\hline
\end{tabular}

N: número de professores incluídos na análise.

Nenhum dos termos de interação avaliados permaneceu no modelo final obtido para os dois desfechos estudados (rouquidão e calos nas cordas vocais).

Após a avaliação multivariada, por meio da regressão logística, as variáveis que permaneceram associadas à rouquidão nos últimos seis meses foram: ter $\geq 24$ horas semanais em sala de aula, trabalhar em duas ou mais escolas, usar a voz gritando e fazer força para falar (Tabela 5). Para a variável de efeito calos nas cordas vocais, as variáveis que permaneceram no modelo final selecionado foram: tempo de trabalho como professor $\geq 5$ anos, trabalhar em duas ou mais escolas, outra atividade remunerada não docente e fazer força para falar (Tabela 6).

\section{Discussão}

A população de professoras estudada é predominantemente jovem e com nível médio de escolaridade, ensinando no ensino fundamental.
A prevalência de rouquidão encontrada foi elevada, alcançando patamares similares aos achados observados entre populações de professores em outros estudos: $57 \%$ entre docentes espanhóis ${ }^{9}$ e $58 \%$ entre professores americanos 14 .

Neste estudo, o tempo de trabalho como docente $\geq 5$ anos estava estatisticamente associado à rouquidão nos últimos seis meses e a diagnóstico referido de calos nas cordas vocais. Achados de literatura mostram resultados divergentes com relação à associação entre alteração vocal e tempo de trabalho. Alguns estudos 15,16 não encontraram associação entre o tempo de serviço e o aparecimento de alteração vocal (disfonia); enquanto outro estudo 17 encontrou associação entre tempo de docência e gravidade da disfonia, principalmente com a intensidade da rouquidão relatada pelos professores. Nosso estudo evidenciou que maior tempo de exposição à atividade docente associa-se a maior freqüência de efeitos negativos sobre a voz, quer sejam efeitos agudos (como rouquidão) ou efeitos mais crônicos (como calos nas cordas vocais). 
Prevalências de rouquidão, razões de prevalências (RP) e intervalos de 95\% de confiança (IC95\%), segundo as categorias das variáveis de exposição significantes, sem e com controle dos efeitos de confundimento, em professoras da rede municipal de ensino de Vitória da Conquista, Bahia, Brasil, 2001.

\begin{tabular}{|c|c|c|c|c|c|c|}
\hline \multirow[t]{2}{*}{ Variável de exposição/Categoria } & \multicolumn{3}{|c|}{$\begin{array}{l}\text { Rouquidão nos últimos seis meses } \\
\text { (sem controle dos efeitos de confundimento) * }\end{array}$} & \multicolumn{3}{|c|}{$\begin{array}{l}\text { Rouquidão nos últimos seis meses } \\
\text { (com controle dos efeitos de confundimento) ** }\end{array}$} \\
\hline & Prevalência (\%) & RP & IC95\% & Prevalência (\%) & $\mathrm{RP}$ & IC95\% \\
\hline \multicolumn{7}{|l|}{ Horas semanais em sala de aula } \\
\hline$\geq 24$ & 63,50 & 1,33 & $1,12-1,58$ & 64,36 & 1,30 & $1,08-1,58$ \\
\hline$<24 * \star \star$ & 47,88 & & & 49,45 & & \\
\hline \multicolumn{7}{|l|}{ Escolas em que trabalha } \\
\hline 2 ou mais & 65,85 & 1,15 & $1,01-1,30$ & 66,40 & 1,14 & $0,99-1,31$ \\
\hline $1 * \star \star$ & 57,46 & & & 58,33 & & \\
\hline \multicolumn{7}{|l|}{ Usa a voz gritando } \\
\hline Sim & 67,22 & 1,27 & $1,13-1,43$ & 62,30 & 1,04 & $0,90-1,20$ \\
\hline Não *** & 52,98 & & & 59,91 & & \\
\hline \multicolumn{7}{|l|}{ Faz força para ser ouvido } \\
\hline Sim & 69,44 & 1,54 & $1,34-1,77$ & 70,94 & 1,55 & $1,32-1,82$ \\
\hline Não *** & 45,03 & & & 45,80 & & \\
\hline
\end{tabular}

* Resultados obtidos após análises bivariadas;

** Resultados obtidos após análises multivariadas; cada modelo final incluiu a variável dependente principal, variável independente principal (considerada uma a cada vez) ajustadas pelas demais variáveis de exposição que permaneceram no modelo final;

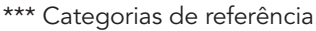

Tabela 6

Prevalências de diagnóstico de calo nas cordas vocais, razões de prevalências (RP) e intervalos de 95\% de confiança (IC95\%), segundo as categorias das variáveis de exposição significantes, sem e com controle dos efeitos de confundimento, em professores da rede municipal de ensino de Vitória da Conquista, Bahia, Brasil, 2001

\begin{tabular}{|c|c|c|c|c|c|c|}
\hline \multirow[t]{2}{*}{ Variável de exposição/Categoria } & \multicolumn{3}{|c|}{$\begin{array}{l}\text { Diagnóstico de calo nas cordas vocais } \\
\text { (sem controle dos efeitos de confundimento) * }\end{array}$} & \multicolumn{3}{|c|}{$\begin{array}{l}\text { Diagnóstico de calo nas cordas vocais } \\
\text { (com controle dos efeitos de confundimento) ** }\end{array}$} \\
\hline & Prevalência (\%) & $\mathrm{RP}$ & IC95\% & Prevalência (\%) & RP & IC95\% \\
\hline \multicolumn{7}{|c|}{ Tempo de trabalho como professor (anos) } \\
\hline$\geq 5$ & 14,54 & 2,44 & $1,21-4,91$ & 13,28 & 2,83 & $1,24-6,49$ \\
\hline 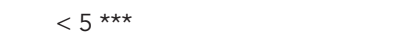 & 5,97 & & & 4,68 & & \\
\hline \multicolumn{7}{|l|}{ Escolas em que trabalha } \\
\hline 2 ou mais & 19,10 & 1,87 & $1,26-2,80$ & 17,46 & 2,01 & $1,29-3,14$ \\
\hline $1 \star \star \star$ & 10,19 & & & 8,68 & & \\
\hline \multicolumn{7}{|c|}{ Outra atividade remunerada não docente } \\
\hline Sim & 27,78 & 2,29 & $1,29-4,05$ & 25,11 & 2,44 & $1,26-4,75$ \\
\hline Não *** & 12,15 & & & 10,28 & & \\
\hline \multicolumn{7}{|l|}{ Faz força para ser ouvido } \\
\hline Sim & 15,94 & 1,66 & $1,09-2,55$ & 14,84 & 2,13 & $1,26-3,58$ \\
\hline Não *** & 9,57 & & & 6,98 & & \\
\hline
\end{tabular}

* Resultados obtidos após análises bivariadas;

** Resultados obtidos após análises multivariadas; cada modelo final incluiu a variável dependente principal, variável independente principal (considerada uma a cada vez) ajustadas pelas demais variáveis de exposição que permaneceram no modelo final;

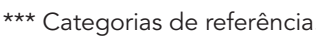


Verificou-se também associação, estatisticamente significante, da queixa de rouquidão nos últimos seis meses com a carga horária $\geq 24$ horas semanais. A carga horária média de trabalho docente encontrada neste estudo está próxima aos resultados relatados por outros pesquisadores que também relacionaram sintomas de alterações vocais com a intensidade da carga horária 17,18. A rouquidão, cansaço ao falar, perda da voz e irritação na garganta foram mais freqüentes entre os professores com mais de 25 horas semanais de trabalho; concluindo-se que o fator horas-aula estava fortemente associado às alterações vocais neste grupo ocupacional. Outro estudo 6 encontrou maior ocorrência de disfonias em professores com até quarenta horas semanais, porém também relatou elevada prevalência em professores com até 25 horas semanais.

O hábito vocal inadequado de fazer força para falar estava fortemente associado às queixas de alterações vocais investigadas (rouquidão nos últimos seis meses e diagnóstico referido de calos nas cordas vocais). Este hábito provavelmente é utilizado para demonstrar firmeza e autoridade junto aos alunos e para vencer a competição sonora do ruído ambiental nas escolas ${ }^{19}$. Freqüentemente, professores apresentam conduta e hábitos inadequados e desconhecem os cuidados preventivos relativos à voz, o que pode contribuir para instalação de um distúrbio vocal 20,21. Portanto, promover treinamento e preparação para o uso adequado da voz aos docentes pode contribuir para reduzir a ocorrência de alterações vocais nesse grupo ocupacional.

Um amplo estudo de corte transversal, realizado em 1.243 professores norte-americanos 14 relatou associação entre alterações vocais e tipo de atividade vocal. As alterações vocais também se associavam no estudo referido a idade, gênero, raça e disciplina ensinada pelo docente.

Em síntese, nossos achados, como observado, evidenciaram associação entre características do trabalho docente e alterações vocais, apontando a necessidade de redimensionamento de algumas dessas características.

$\mathrm{Na}$ análise de nossos achados, devem-se também considerar algumas de possíveis limitações. Os estudos de corte transversal caracteristicamente apresentam dois tipos de limitações: só incluem aqueles indivíduos que sobreviveram à doença e, por coletarem simultaneamente dados de exposição e de doença, têm dificuldade para estabelecer uma relação de causalidade entre ambos. As alterações vocais avaliadas na nossa pesquisa são crônicas, recorrentes, ou não letais, assim dificilmente se perderam casos pelo primeiro tipo de viés. Contudo, devem ser considerados possíveis vieses de seleção, especialmente o decorrente do chamado efeito trabalhador sadio. Assim, devese levar em conta as possibilidades de perda de informação daquelas professoras que: (1) abandonaram a profissão em decorrência de alguma doença ou desgaste relacionado ao trabalho; ou (2) estariam ausentes do trabalho à época da coleta de dados por alguma razão de saúde, uma delas sendo a incapacidade laborativa decorrente de manifestação da disfonia. A época de maior absenteísmo para os professores é o final do ano escolar 22, período em que os dados foram coletados. Nesta última possibilidade, os nossos dados estariam subestimando a real prevalência da morbidade.

Pesquisas baseadas em questionários respondidos e completados pelos próprios respondentes, como é o caso deste estudo, possibilitam a ocorrência de viés de auto-relato, o que deve ser considerado na discussão de quaisquer resultados que envolvam esse tipo de instrumento de pesquisa.

No contexto deste estudo transversal, é difícil o estabelecimento de relação temporal clara entre "exposição" (avaliada como "fazer força para falar" ou "gritar") e "efeito" (avaliado como "rouquidão" ou "calos nas cordas vocais"). Contudo, deve-se considerar que as possibilidades de causa reversa, no caso dos efeitos estudados neste estudo, são muito restritas, sendo pouco provável que uma professora com alteração vocal aumente o número de horas em sala de aula/semana ou passe a lecionar em mais de uma escola. Por fim, não se pode afastar a possibilidade de que as supostas "exposições", avaliadas como hábitos vocais, tenham decorrido, em última instância, do mesmo conjunto sindrômico que define estas alterações da voz (rouquidão e calos nas cordas vocais).

Os fatores de risco para o adoecimento vocal mais comumente listados pela literatura científica são de cunho biológico (predisposição hereditária) ou relativos aos hábitos individuais (falta de uma educação vocal apropriada). O presente estudo, entretanto, evidenciou a importância dos fatores associados à forma e à intensidade com que o trabalho docente é executado, indicando a necessidade de redimensionamento de alguns aspectos do trabalho docente, como por exemplo, do tempo durante o qual se usa a voz profissionalmente. Os fatores associados à ocorrência de alterações vocais, apontados aqui, devem, assim, ser considerados na formulação e na execução de medidas preventivas do adoecimento vocal das professoras. 


\section{Resumo}

Objetivou-se identificar fatores associados a alterações vocais (rouquidão nos últimos seis meses, como uma manifestação inicial, e calo nas cordas vocais, como uma manifestação mais severa, de doença já instalada) entre professoras. Um estudo epidemiológico de corte transversal investigou 747 professoras da rede municipal de ensino de Vitória da Conquista, Bahia, Brasil, coletando dados num formulário padronizado, auto-aplicado. A queixa de rouquidão nos últimos seis meses foi referida por $59,2 \%$ das professoras e a do diagnóstico médico de calo nas cordas vocais, por 12,9\%. Técnicas de regressão logística revelaram que rouquidão nos últimos seis meses estava estatisticamente associada a trabalhar $\geq 24$ horas em sala de aula, trabalhar em mais de uma escola e fazer força para falar. A queixa de calo nas cordas vocais estava associada a trabalhar $\geq 5$ anos como docente, trabalhar em mais de uma escola, trabalhar em outra atividade além da docência e fazer força para falar. Conclui-se que alterações vocais são freqüentes nesta população e estão associadas a múltiplos fatores ocupacionais, além daqueles de cunho fundamentalmente biológico.

Cordas Vocais; Distúrbios da Voz; Condições de Trabalho

\section{Colaboradores}

E. J. F. B. Reis participou da coordenação geral da pesquisa e do trabalho de campo, análise dos dados e redação do manuscrito. T. M. Araújo colaborou na coordenação geral da pesquisa, orientação geral e revisão do manuscrito. F. M. Carvalho contribuiu na orientação geral, redação e revisão do manuscrito. L. A. Porto trabalhou na análise de dados, revisão do manuscrito. I. C. Reis e J. M. Andrade participaram da coleta dos dados, digitação dos dados, revisão bibliográfica e redação do manuscrito.

\section{Referências}

1. Heidel SE, Torgerson JK. Vocal problems among aerobic instructors and aerobic participants. J Commun Disord 1993; 26:179-91.

2. Boone DR, McFarlane SC. A voz e a terapia vocal. Porto Alegre: Editora Artes Médicas; 1994.

3. Organización Internacional del Trabajo. Empleo y condiciones de trabajo del personal docente. Genebra: Organización Internacional del Trabajo; 1983.

4. Yiu EM-L. Impact and prevention of voice problems in the teaching profession: embracing the consumers' view. J Voice 2002; 16:215-28.

5. Duffy OM, Hazlett DE. The impact of preventive voice care programs for training teachers: a longitudinal study. J Voice 2004; 18:63-70.

6. Colton RH, Casper JK. Compreendendo os problemas da voz: uma perspectiva fisiológica ao diagnóstico e ao tratamento. Porto Alegre: Editora Artes Médicas; 1996.
7. Scalco MAG, Pimentel RM, Pilz W. A saúde vocal do professor: levantamento junto a escolas particulares de Porto Alegre. Pró-fono 1996; 8:25-30.

8. Preciado J, Pérez C, Calzada M, Preciado P. Frequencia y factores de riesgo de los transtornos de la voz en el personal docente de La Rioja. Estudio transversal de 527 docentes: cuestionario, examen de la función vocal, análisis acústico y vídeolaringoestroboscopia. Acta Otorrinolaringol Esp 2005; 56:161-70.

9. Preciado J, Pérez C, Calzada M, Preciado P. Incidencia y prevalencia de los trastornos de la voz en el personal docente de La Rioja. Estudio clínico: cuestionario, examen de la función vocal, análisis acústico y vídeolaringoestroboscopia. Acta Otorrinolaringol Esp 2005; 56:202-10. 
10. Krischke S, Weigelt S, Hoppe U, Köllner V, Klotz M, Eysholdt U, et al. Quality of life in dysphonic patients. J Voice 2005; 19:132-7.

11. Karasek RA. Job content questionnaire and user's guide. Lowell: University of Massachusetts; 1985.

12. Hosmer DW, Lemeshow S. Applied logistic regression. New York: John Wiley and Sons; 1989.

13. Oliveira NF, Santava VS, Lopes AA. Razões de proporções e uso do método delta para intervalos de confiança em regressão logística. Rev Saúde Pública 1997; 31:90-9.

14. Thibeault SL, Merrill RM, Roy N, Gray SD, Smith EM. Occupational risk factors associated with voice disorders among teachers. Ann Epidemiol 2004; 14:786-92.

15. Bruneto B, Oyarzun R, Mella L, Avila S. Mitos y realidades de la disfonia profissional. Rev Otorrinolaringol Cir Cabeza Cuello 1986; 46:115-20.

16. Andrade EC. Pesquisa de alterações vocais em professores de 1a a $4 \underline{a}$ série da rede municipal de ensino de Belo Horizonte (RMEBH): dados, estimativas e correlações. Revista de Fonoaudiologia 1994; 1:24-9.
17. Souza TMT, Ferreira LP. O professor e sua voz: um difícil encontro. In: Behlau M, organizadora. Laringologia e voz hoje. Rio de Janeiro: Editora Revinter; 2000. p. 452-3.

18. Sapir S, Keidar A, Mathers-Schimdt B. Vocal attrition in teachers: survey findings. Eur J Disord Commun 1993; 28:177-85.

19. Martz MLW. Os usos sociais da voz. Revista Distúrbios da Comunicação 1987; 2:173-6.

20. Penteado RZ, Pereira IMTB. A voz do professor: relações entre trabalho, saúde e qualidade de vida. Rev Bras Saúde Ocup 1999; 25:109-30.

21. Russell A, Oates J, Greenwood KM. Prevalence of voice problems in teachers. J Voice 1998; 12:467-79.

22. Esteve JM. O mal-estar docente: a sala de aula e a saúde dos professores. 2a Ed. São Paulo: EDUSC; 1999.

Recebido em 13/Jul/2006

Versão final reapresentada em 18/Jun/2007

Aprovado em 21/Nov/2007 